\title{
SEQUENTIAL MULTI-ELEMENT DETERMINATION OF TRACE-METALS IN BIODIESEL SAMPLES USING HR-CS FAAS
}

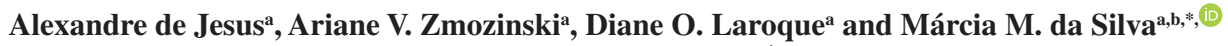 \\ ${ }^{a}$ Centro de Combustíveis, Biocombustíveis, Lubrificantes e Óleos, Instituto de Química, Universidade Federal do Rio Grande do \\ Sul, 91501-970 Porto Alegre - RS, Brasil \\ ${ }^{\mathrm{b}}$ Instituto Nacional de Ciência e Tecnologia do CNPq, INCT de Energia e Ambiente, Universidade Federal da Bahia, 40170-115 \\ Salvador - BA, Brasil
}

Recebido em 13/05/2020; aceito em 24/07/2020; publicado na web em 26/11/2020

\begin{abstract}
In this work the feasibility of sequential multi-element determination of $\mathrm{Zn}, \mathrm{Fe}, \mathrm{Mg}, \mathrm{Cu}, \mathrm{Na}, \mathrm{K}, \mathrm{Cr}, \mathrm{Al}$ and $\mathrm{Ca}$ in biodiesel samples by high-resolution continuum source flame atomic absorption spectrometry (HR-CS FAAS) was investigated. Biodiesel samples obtained from different sources and different chemical processes were analysed. The samples were diluted with $n$-propanol and water (1.4 mol L-1 $\mathrm{HNO}_{3}$ ) to form a microemulsion (ME) before its introduction in the HR-CS FAAS using a flow injection mode. The sample B-01 (obtained from soybean oil) was used for optimisation of the instrumental parameters. The accuracy of the proposed method was checked by analysis of certified reference material (CRM) Conostan BDM2A (for K and Na) and BDM2B (for Ca and $\mathrm{Mg}$ ) and by comparison with acid digestion and recovery tests (for $\mathrm{Zn}, \mathrm{Fe}, \mathrm{Cu}, \mathrm{Cr}$ and $\mathrm{Al}$ ). The obtained results for $\mathrm{CRM}$ analysis showed good agreement with certified values within $95 \%$ of confidence (Student's $t$-test). Recovery tests values ranged from $87-114 \%$. The method developed for the analysis of biodiesel samples is accurate, simple, fast, and suitable for routine application.
\end{abstract}

Keywords: biodiesel analysis; microemulsion; sequential multi-element determination; HR-CS FAAS.

\section{INTRODUCTION}

The use of alternative fuels, rather than petroleum products, has been gaining a prominence in the scientific community in recent years. In this way, the use of biofuels, especially biodiesel, is becoming increasingly used in the world. ${ }^{1,2}$ Brazil is one of the countries with the greatest potential for biodiesel production in the world, since it has a large extension of land with the cultivation of many oilseeds. ${ }^{1}$ In Brazil, since 2005, diesel oil marketed in the country is blended with biodiesel. The initial percentage of biodiesel was $2 \%(\mathrm{v} / \mathrm{v})$ and it will be increased in the next years until the maximum of $15 \%(\mathrm{v} / \mathrm{v}){ }^{3}$ Currently the amount of biodiesel blended into diesel oil is $12 \%(\mathrm{v} / \mathrm{v})$ according Brazilian National Petroleum Agency (ANP). ${ }^{3}$

The presence of metals in biodiesel may increase (additives) or may impair its performance. Some metals can catalyse the oxidation reactions of biodiesel, reducing its efficiency and thermal stability. Other metals can damage catalytic converters leading to an increase in the emission of pollutants into the atmosphere, and can also cause the formation of residues that could be deposited on the engine parts. ${ }^{4}$ The presence of metals in biodiesel can occur through natural sources, such as the soil and the atmosphere where the grains grow. ${ }^{5}$ Other metals can be added in the steps of oil extraction, synthesis, washing, refining and biodiesel storage ${ }^{6} \mathrm{Cu}$ and $\mathrm{Ni}$ are known to promote self-oxidative reactions, compromising fuel efficiency due to the formation of gums. ${ }^{7}$ These elements also reduce the efficiency of the car catalysts, resulting in an increase in the emission of carbon monoxide and oxides of sulphur and nitrogen. $\mathrm{Fe}, \mathrm{Cu}, \mathrm{Al}$ and $\mathrm{Cr}$ present in the alloys of the storage tanks and the distillation process are also known to corrode engines and boilers. ${ }^{7}$ Thus, the monitoring of the concentration of metals is very important to guarantee the quality and efficiency of the biodiesel. ${ }^{7}$

The initial procedures of an analytical method are responsible for the accuracy of the chemical information. The sample

*e-mail: mmsilva@iq.ufrgs.br preparation phases required for the determination of metals in biodiesel matrices through spectroanalytical techniques include wet digestion (conventional and microwave heating), emulsions and microemulsions (ME) or dilution with organic solvents. ${ }^{6,8}$ The use of $\mathrm{ME}$ is a very interesting strategy in the preparation of biodiesel samples for the determination of metals, since it requires low amount of solvents and/or other toxic reagents, besides having an excellent stability. ${ }^{9}$ The use of aqueous standards in the ME for calibration is another advantage. ${ }^{10} \mathrm{ME}$ are defined as spherical oil (or water) aggregates dispersed in water (or oil) and stabilized by an interfacial film of a surfactant. ${ }^{11}$ Microemulsions are stable, transparent, isotropic and with low viscosity. ${ }^{12}$ Besides, it is an efficient way to stabilize metals at low concentrations in organic solutions, especially if nitric acid is present in the aqueous phase..$^{13}$ Due to these advantages, several methods based on ME have been proposed for trace elements determination in biodiesel. ${ }^{6,8,14,15}$

Several analytical techniques have been used for the determination of elements in biodiesel samples: flame atomic absorption spectrometry (FAAS), ${ }^{15,16}$ electrothermal atomic absorption spectrometry (ETAAS), ${ }^{17}$ inductively coupled plasma optical emission spectrometry (ICP OES), ${ }^{4,18}$ inductively coupled plasmamass spectrometry (ICP-MS), ${ }^{19,20}$ high-resolution continuum source flame atomic absorption spectrometry (HR-CS FAAS) ${ }^{21,22}$ and high-resolution continuum source electrothermal atomic absorption spectrometry (HR-CS ETAAS). ${ }^{1,7}$

The HR-CS AAS, which was introduced commercially in $2004,{ }^{23}$ is an excelent alternative technique for the determination of trace elements in biodiesel samples. In the case of FAAS with line source, only one element can be determined at time, requiring the lamp change and the adjustment of the equipment conditions for each analysis. The HR-CS FAAS technique allows sequential multi-element determination using a single radiation source and a high resolution spectrometer. The spectral environment of $\pm 0.2 \mathrm{~nm}$ around the analytical line becomes accessible by employing a detector with a charge coupled device (CCD) array of about 2 pm per pixel, 
allowing revelation and efficient correction of interferences of other elements or gaseous molecules. ${ }^{24}$ Moreover, the equipment's software automatically adjust the optimal operating conditions for each element, instead of using a compromise condition for multi-element analysis. These advantages, added to the robustness of flame for organic liquids analysis and the lower cost of implemantation and operation, make this technique competitive with other multi-element techniques such as ICP OES and very attractive for a fast sequential multi-element determination of metals in fuels and biofuels. To the best of our knowledge, the sequential determination of $\mathrm{Zn}, \mathrm{Fe}, \mathrm{Mg}$, $\mathrm{Cu}, \mathrm{Na}, \mathrm{K}, \mathrm{Cr}, \mathrm{Al}$ and $\mathrm{Ca}$ in biodiesel samples by HR-CS FAAS has not been reported until now.

The goal of this work was the development of a simple, fast, and accurate analytical method using HR-CS FAAS, which can be applied routinely in the determination of $\mathrm{Zn}, \mathrm{Fe}, \mathrm{Mg}, \mathrm{Cu}, \mathrm{Na}, \mathrm{K}, \mathrm{Cr}, \mathrm{Al}$ and $\mathrm{Ca}$ in biodiesel samples. The sample preparation evaluated consisted in the formation of ME through a simple mixture of biodiesel, aqueous phase and $n$-propanol. The feasibility of sequential multi-element determination was investigated. The accuracy of the method has been investigated by CRM analysis, comparison with acid digestion and recovery tests.

\section{EXPERIMENTAL}

\section{Instrumentation}

All measurements were carried out using in a Model ContrAA 300 high-resolution continuum source flame atomic absorption spectrometer (Analytik Jena AG, Germany), equipped with a xenon short-arc lamp with a nominal power of $300 \mathrm{~W}$ operating in a hotspot mode. The high-resolution double monochromator had a prism pre-monochromator, a high-resolution echelle monochromator and a CCD array detector with 588 pixels, 200 of which were used for analytical purposes. The wavelength used for each element is detailed in Table 1. An air-acetylene flame was used for the determination of $\mathrm{Zn}, \mathrm{Fe}, \mathrm{Mg}, \mathrm{Cu}, \mathrm{Na}$ and $\mathrm{K}$ and a nitrous oxide-acetylene flame for $\mathrm{Cr}, \mathrm{Al}$ and $\mathrm{Ca}$ under optimized conditions as specified in Table 1 . The compressed air was supplied from an air compressor (FIAC CDS 8/50, Araraquara, São Paulo, Brazil). High-purity acetylene and high-purity nitrous oxide (both $99.0 \%$ v/v, White Martins, Brazil) were used as fuel and oxidant gas, respectively. A flow injection valve SFS 6 (Analytik Jena) was used with the following parameters: aspiration rate of $2.8 \mathrm{~mL} \mathrm{~min}^{-1}$, injection time of $2.0 \mathrm{~s}$ and reading time of $13 \mathrm{~s}$ (for ME analysis). For the measurement of standards prepared in water and digested spiked-samples (from acid digestion) an aspiration rate of $5.8 \mathrm{~mL} \mathrm{~min}^{-1}$, injection time of $1.5 \mathrm{~s}$ and reading time of $10 \mathrm{~s}$ were applied. As the signal generated were transient, integrated absorbance
$\left(\mathrm{A}_{\text {int }}\right)$ of the center pixel $(\mathrm{CP})$ and the two adjacent pixels $(\mathrm{CP} \pm 1)$ were measured for all elements. All measurements were carried out in triplicate. An analytical balance model ATY-224 (Shimadzu, Kyoto, Japan) was used to weigh samples and reagents.

\section{Reagents, solutions and samples}

Analytical grade reagents were exclusively used. Deionised water with a specific resistivity of $18 \mathrm{M} \Omega \mathrm{cm}$ from a Milli-Q water purification system (Millipore, Bedford, MA, USA) was used for the preparation of standards and samples.

Nitric acid (Merck, Darmstadt, Germany), n-propanol (Synth, São Paulo, Brazil), mineral-based oil (Light mineral oil, $20 \mathrm{cSt}$, High Purity Standards, Charleston, USA) and oleic acid (Vetec, Rio de Janeiro, Brazil) were employed in the ME preparation. The $n$-propanol was distilled at $97{ }^{\circ} \mathrm{C}$. The nitric acid was purified by sub-boiling distillation in a quartz distiller (Kürner Analysentechnik, Rosenheim, Germany). The presence of analytes in the oleic acid and in the purified reagents was checked through the blank analysis. The signal found (<LOD) demonstrated that the $n$-propanol and nitric acid were properly purified and that there is no need for purification of oleic acid. All containers and glassware were soaked in $1.4 \mathrm{~mol} \mathrm{~L}^{-1}$ nitric acid for 24 hours and rinsed with deionised water before use. Hydrogen peroxide 30\% (v/v) (Merck) was used in the spikedsamples digestion. Mineral oil was used to dilute stock standards in oil. Inorganic aqueous stock solutions of $1000 \mathrm{mg} \mathrm{L}^{-1}$ of $\mathrm{Zn}, \mathrm{Fe}, \mathrm{Mg}$, $\mathrm{Cu}, \mathrm{Na}, \mathrm{K}, \mathrm{Cr}, \mathrm{Al}$ and $\mathrm{Ca}$ were prepared from Conostan standards (Baie D'Urfé, Quebec, Canada). Organic stock solutions of $1000 \mathrm{mg}$ $\mathrm{kg}^{-1}$ of $\mathrm{Zn}, \mathrm{Fe}, \mathrm{Mg}, \mathrm{Cu}, \mathrm{Na}, \mathrm{K}, \mathrm{Cr}, \mathrm{Al}$ and $\mathrm{Ca}$ were prepared from Specsol standards (Jacareí, São Paulo, Brazil).

The biodiesel samples analysed have the following origins: soybean oil (B-01 e B-02), mixtures of soybean oil and animal fats (M-01, M-02, M-03, M-04 e M-05), used cooking oil (C-01, C-02 and C-03). Certified reference materials of biodiesel: BDM2A (Ref: 150-441-060) containing $50 \mathrm{mg} \mathrm{kg}^{-1}$ of $\mathrm{K}$ and $\mathrm{Na}$; and BDM2B (Ref: 150-441-095) containing $50 \mathrm{mg} \mathrm{kg}^{-1}$ of $\mathrm{Ca}$ and $\mathrm{Mg}$, both from Conostan, were also analysed.

\section{Preparation of ME and analysis}

The ME was prepared by mixing biodiesel, aqueous phase (1.4 mol L-1 $\mathrm{HNO}_{3}$ ) and $n$-propanol. The composition adopted for the analysis was investigated and optimized in a previous work: ${ }^{15}$ $1.7 \mathrm{~g}$ of biodiesel, $1100 \mu \mathrm{L}$ of aqueous phase and the volume adjusted to $10 \mathrm{~mL}$ with $n$-propanol. After addition of all components, the volumetric flask was closed and the mixture was manually shaken for 15 seconds. The formation of ME was evidenced by obtaining a

Table 1. Instrumental parameters used for HR-CS FAAS measurements

\begin{tabular}{|c|c|c|c|c|c|}
\hline Analyte & Wavelength (nm) & Relative sensitivity $(\%)^{\mathrm{a}}$ & Flame & $\mathrm{C}_{2} \mathrm{H}_{2}$ flow rate $\left(\mathrm{L} \mathrm{h}^{-1}\right)$ & Burner height (mm) \\
\hline $\mathrm{Zn}$ & 213.857 & 100 & $\mathrm{C}_{2} \mathrm{H}_{2}-\mathrm{Ar}$ & 65 & 5 \\
\hline $\mathrm{Fe}$ & 248.327 & 100 & $\mathrm{C}_{2} \mathrm{H}_{2}-\mathrm{Ar}$ & 100 & 6 \\
\hline $\mathrm{Mg}$ & 285.212 & 100 & $\mathrm{C}_{2} \mathrm{H}_{2}-\mathrm{Ar}$ & 55 & 6 \\
\hline $\mathrm{Cu}$ & 324.754 & 100 & $\mathrm{C}_{2} \mathrm{H}_{2}-\mathrm{Ar}$ & 90 & 6 \\
\hline $\mathrm{Na}$ & 588.995 & 100 & $\mathrm{C}_{2} \mathrm{H}_{2}-\mathrm{Ar}$ & 80 & 6 \\
\hline $\mathrm{K}$ & 766.490 & 100 & $\mathrm{C}_{2} \mathrm{H}_{2}-\mathrm{Ar}$ & 70 & 4 \\
\hline $\mathrm{Cr}$ & 357.868 & 100 & $\mathrm{C}_{2} \mathrm{H}_{2}-\mathrm{N}_{2} \mathrm{O}$ & 245 & 9 \\
\hline $\mathrm{Al}$ & 396.152 & 91 & $\mathrm{C}_{2} \mathrm{H}_{2}-\mathrm{N}_{2} \mathrm{O}$ & 170 & 4 \\
\hline $\mathrm{Ca}$ & 422.672 & 100 & $\mathrm{C}_{2} \mathrm{H}_{2}-\mathrm{N}_{2} \mathrm{O}$ & 170 & 8 \\
\hline
\end{tabular}

${ }^{a}$ Compared to the main resonance line for this element. 
visual transparent system. All samples were prepared in triplicate.

The ME standards for calibration were prepared similarly to the samples, where the biodiesel was replaced by $0.9 \mathrm{~g}$ of oleic acid and the aqueous inorganic standards added to the aqueous phase. The optimization of oleic acid mass used will be discussed in the results (Microemulsions for calibration curves section). The following concentration ranges in $\mathrm{mg} \mathrm{L}^{-1}$ were used: $0.1-0.7$ for $\mathrm{Zn}, 0.6-4.2$ for $\mathrm{Fe}, 0.06-0.42$ for $\mathrm{Mg}$ and $\mathrm{K}, 0.45-3.15$ for $\mathrm{Cu}, 0.02-0.14$ for $\mathrm{Na}$, 0.7-4.9 for $\mathrm{Cr}, 2.8-19.6$ for $\mathrm{Al}$ and 0.05-0.35 for $\mathrm{Ca}$.

As each CRM is certified for two elements (BDM2A for $\mathrm{Na}$ and $\mathrm{K}$ and $\mathrm{BDM} 2 \mathrm{~B}$ for $\mathrm{Ca}$ and $\mathrm{Mg}$ ), both were prepared together, in the same ME, in order to perform a multi-element analysis. Due to the high concentration of the analytes in the CRM, only $0.05 \mathrm{~g}$ of mass of each CRM and $0.8 \mathrm{~g}$ of oleic acid (for matrix adjustment) were weight and $1100 \mu \mathrm{L}$ of aqueous phase were added and the volume adjusted to $10 \mathrm{~mL}$ with $n$-propanol.

After preparation, samples, CRM and standards MEs were directly aspirated for analysis.

\section{Recovery tests and acid digestion procedure}

Recovery tests were performed to investigate the matrix effect. The enrichment of samples for recovery tests was carried out by addition of organic standards under vigorous agitation and light heating $\left(40{ }^{\circ} \mathrm{C}\right)$; the process of mixture took around of 3 hours, in order to obtain a homogeneous concentration of analytes in the enriched samples. Samples B-01 and M-01 were spiked with organic standards resulting in the following concentrations: Spike 1: $0.25 \mathrm{mg} \mathrm{L}^{-1} \mathrm{Zn} ; 1.2 \mathrm{mg} \mathrm{L}^{-1} \mathrm{Fe} ; 1.0 \mathrm{mg} \mathrm{L}^{-1} \mathrm{Cu} ; 1.75 \mathrm{mg} \mathrm{L}^{-1} \mathrm{Cr}$ and $8.0 \mathrm{mg} \mathrm{L}^{-1} \mathrm{Al}$; Spike 2: $0.50 \mathrm{mg} \mathrm{L}^{-1} \mathrm{Zn} ; 2.4 \mathrm{mg} \mathrm{L}^{-1} \mathrm{Fe} ; 2.0 \mathrm{mg} \mathrm{L}^{-1}$ $\mathrm{Cu} ; 3.5 \mathrm{mg} \mathrm{L}^{-1} \mathrm{Cr}$ and $14.0 \mathrm{mg} \mathrm{L}^{-1} \mathrm{Al}$. Afterwards the spiked samples were analysed through the proposed method, prepared as described above and also digested in concentrated acid. The acid digestion method, based on the work of Antunes et al., ${ }^{15}$ was used for accuracy evaluation. All steps were performed in a digester block using a "cold finger". A mass of $1.0 \mathrm{~g}$ of sample was weighed directly into an open glass tubes and $10.0 \mathrm{~mL}$ of concentrated nitric acid was added. The mixture was gradually heated up to $120^{\circ} \mathrm{C}$ and then kept for $30 \mathrm{~h}$. After that, the tubes were left to cool into room temperature and $2.5 \mathrm{~mL}$ of hydrogen peroxide $(30 \% \mathrm{v} / \mathrm{v})$ was added and the tubes were left to rest during an hour to complete the digestion. The digestion products were transferred to volumetric flasks and the volume was completed up to $40 \mathrm{~mL}$ with ultrapure water. All samples were digested in triplicate. The calibration curves for the digested sample were prepared by serial dilutions from aqueous stock solutions $\left(1000 \mathrm{mg} \mathrm{L}^{-1}\right)$ of the analytes in $0.014 \mathrm{~mol} \mathrm{~L}^{-1}$ nitric acid in the same range of concentrations of the ME method.

Recovery tests were also performed using inorganic standards. In these experiments, the standards were added to the aqueous phase during the ME preparation. The sample M-02 was fortified in the following concentrations: $0.50 \mathrm{mg} \mathrm{L}^{-1} \mathrm{Zn}, 3.00 \mathrm{mg} \mathrm{L}^{-1} \mathrm{Fe}$, $0.30 \mathrm{mg} \mathrm{L}^{-1} \mathrm{Mg}, 2.25 \mathrm{mg} \mathrm{L}^{-1} \mathrm{Cu}, 0.10 \mathrm{mg} \mathrm{L}^{-1} \mathrm{Na}, 0.30 \mathrm{mg} \mathrm{L}^{-1} \mathrm{~K}$, $3.50 \mathrm{mg} \mathrm{L}^{-1} \mathrm{Cr}, 14.00 \mathrm{mg} \mathrm{L}^{-1} \mathrm{Al}$ and $0.25 \mathrm{mg} \mathrm{L}^{-1} \mathrm{Ca}$.

\section{RESULTS AND DISCUSSION}

\section{Microemulsion preparation and optimization of instrumental parameters}

As stated before, the feasibility of multi-element determination of nine elements in biodiesel samples by HR-CS FAAS in a flow injection mode was investigated. The sample preparation using $\mathrm{ME}$ was based on the work of Antunes et al. using water $/ \mathrm{HNO}_{3}$ and $n$-propanol. ${ }^{15}$ This method was chosen because of the reported advantages such as being simple, fast and because of the high stability of ME and analytes in the system. An adaptation was made in the ME for calibration (standards), as will be shown later.

The optimization of the spectrometer experimental conditions for sequential multi-element analysis was performed using continuous flow mode, with a biodiesel sample (B-01) enriched with liposoluble standards of each analyte prepared as ME. This sample was chosen considering the absence of any analytical signal for the studied analytes and also the raw material of production, soybean oil, which is the most common source for biodiesel in Brazil. Sequential measurements of analytes were performed according to the following sequence: $\mathrm{Zn}, \mathrm{Fe}, \mathrm{Mg}, \mathrm{Cu}, \mathrm{Na}, \mathrm{K}, \mathrm{Cr}, \mathrm{Al}$ and $\mathrm{Ca}$. This sequence was chosen according to the wavelength of analytes (from lowest to the highest) and flame composition, first the elements analysed in air- $\mathrm{C}_{2} \mathrm{H}_{2}(\mathrm{Zn}, \mathrm{Fe}, \mathrm{Mg}, \mathrm{Cu}, \mathrm{Na}$ e $\mathrm{K})$ and following the elements analysed in $\mathrm{N}_{2} \mathrm{O}-\mathrm{C}_{2} \mathrm{H}_{2}$ flame $(\mathrm{Cr}, \mathrm{Al}$ and $\mathrm{Ca})$. Flame conditions and burner height were automatically optimized by the software, taking maximum absorbance into account as a criterion. The highest aspiration rate possible was used $\left(2.8 \mathrm{~mL} \mathrm{~min}^{-1}\right)$, since later a valve would be used to inject the samples. The optimized conditions as burner height, acetylene flow rate, wavelength and relative sensitivity for signal evaluation for each analyte are presented in Table 1 . The $396.152 \mathrm{~nm}$ line (91\% of relative sensitivity) was used for Al, instead of $309.271 \mathrm{~nm}$ line (100\% of relative sensitivity) because of the interferences of the $\mathrm{OH}$ structures in the main line for this element. ${ }^{24}$

After the optimization of instrumental parameters using continuous flow mode, the use of a flow injection valve (SFS 6) was evaluated. The use of the flow injection valve controls the injection of the solution, passing from the sample to the water (carrier solution) and vice versa, avoiding influences on the flame stability, as no air is aspirated between the samples. ${ }^{25}$ This feature should result in better analytical precision. Another important feature of the valve is the reduction in consumption and sample load in the flame. As part of the optimization of instrumental parameters, a Gaussian peak free of spectral interference is required. Injection volumes were tested for the following times: $0.5 ; 1.0 ; 1.5$ and 2.0 seconds, with a choice of 2.0 seconds due to the best integrated absorbance and peak format, as shown in Figure 1 for $\mathrm{Cu}$. Longer times have not been investigated in order to avoid increasing the total analysis time.The total sample volume used for each sample injection replicate using the flow injection valve was $90 \mu \mathrm{L}$. The total volume used to determine all

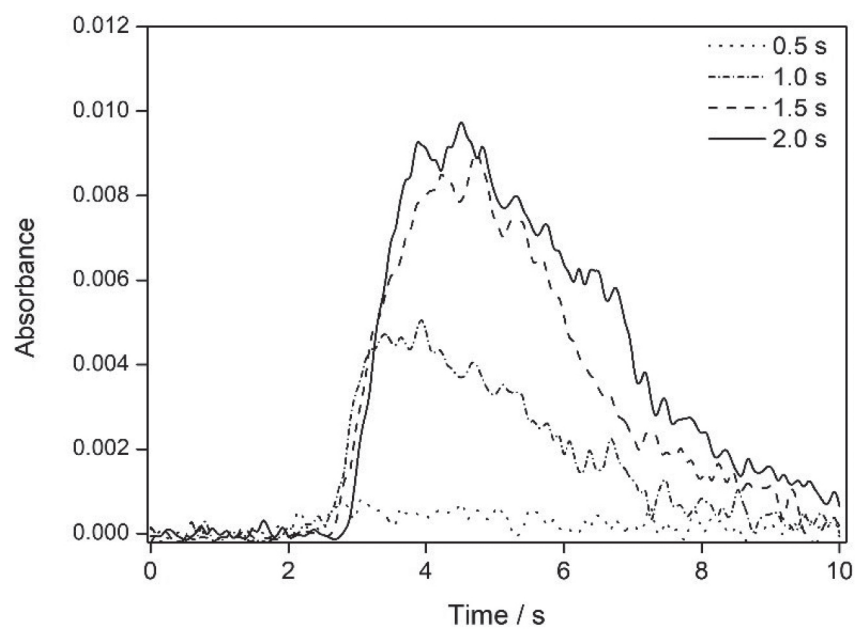

Figure 1. Overlaid transient signals for $1.0 \mathrm{mg} \mathrm{L}^{-1} \mathrm{Cu}$ at different injection times. Microemulsion composition: $1.7 \mathrm{~g}$ of enriched sample B-01, $1100 \mu \mathrm{L}$ aqueous phase (1.4 mol $\mathrm{L}^{-1} \mathrm{HNO}_{3}$ ) and n-propanol (up to $10 \mathrm{~mL}$ ). Instrumental parameters at Table 1 
analytes, considering measurements in triplicate for each analyte, was around of $2.5 \mathrm{~mL}$. The total time to determine nine analytes in each sample, using measurements in triplicate for each analyte, was around $13 \mathrm{~min}$. This relatively long time was due to the adjustment of wavelengths and flame parameters. Additional time is also needed to stabilize the flame after changing its composition between air- $\mathrm{C}_{2} \mathrm{H}_{2}$ and $\mathrm{N}_{2} \mathrm{O}-\mathrm{C}_{2} \mathrm{H}_{2}$. But it should be pointed out that, if conventional monoelementar FAAS were used for this analysis, the total time for the determination of all analytes would be much longer. The analytical signals obtained for all analytes were free of spectral interferences and similar to those shown in Figure 1S (at Supplementary Material).

\section{Microemulsions for calibration curves}

In order to prevent interferences in the nebulization and transport, ${ }^{8}$ calibration curves standards should have similar physical characteristics to the samples. In a previous work ${ }^{15}$ oleic acid was proposed as a substitute for the sample in the preparation of the ME for calibration, due to its chemical and physical similarity with biodiesel. ${ }^{26}$ Nevertheless, when calibration curves were prepared replacing the biodiesel by the same amount of oleic acid in the ME, the sensitivity were lower (15-30\%) for the elements $\mathrm{Na}, \mathrm{K}, \mathrm{Ca}$ and $\mathrm{Mg}$. Thus, the analytical signal obtained for ME prepared with $\mathrm{K}$ and $\mathrm{Mg}$ aqueous standards and biodiesel sample (B-01) free of analytes were compared with those obtained for MEs prepared with the same aqueous standards and oleic acid, in different proportions. The best results were obtained when the sample was replaced by $0.9 \mathrm{~g}$ of oleic acid (see Figure $2 \mathrm{~S}$ at Suplementary Material). Consequently, the standards for calibration were prepared in the same way as the samples, replacing the biodiesel by $0.9 \mathrm{~g}$ of oleic acid to simulate the biodiesel matrix in the ME and adding the inorganic standards into the aqueous phase.

\section{Figures of merit}

The sensitivity of the method, obtained from the linear regression equation of the calibration curves prepared according to the description above, and the correspondent correlation coefficient are shown in Table 2.

The limits of detection (LOD) and quantification (LOQ) for all analytes were calculated according to IUPAC recommendations as three times and ten times, respectively, the standard deviation of 10 measurements of a blank, divided by the slope of the calibration curve. LOD and LOQ of the method were calculated considering the sample mass and final volume. The characteristic concentration, $\mathrm{C}_{0}$, (Table 2) is defined as the concentration of an analyte that produces an integrated absorbance signal of 0.0044 s. For all investigated elements, the linear correlation coefficients presented values higher than 0.99 and the LOD and LOQ were appropriate to determine the elemental composition of the biodiesel samples. The figure of merit obtained by the proposed method (ME) presented values of LOD similar to other works reported in the literature using flame spectrometric techniques. ${ }^{13,14-16,21}$

Since there is no biodiesel reference material certified for $\mathrm{Zn}, \mathrm{Fe}$, $\mathrm{Cu}, \mathrm{Cr}$ and $\mathrm{Al}$, the accuracy of the proposed method was evaluated by recovery tests of the analytes added in the sample and comparison with digestion method. Organic standards of $\mathrm{Zn}, \mathrm{Fe}, \mathrm{Cu}, \mathrm{Cr}$ and $\mathrm{Al}$ were added in samples B-01 and M-01 in two levels (spike 1 and spike 2) as described in the experimental section. The samples were then homogenized and separated in two aliquots: one for ME preparation and another for acid digestion. The results obtained by both methods for $\mathrm{Zn}$, $\mathrm{Fe}, \mathrm{Cu}, \mathrm{Cr}$ and $\mathrm{Al}$ elements in the spiked samples are shown in Table 3.

The concentrations of the measured analytes did not show significant differences (at a 95\% confidence level), according to

Table 2. Figures of merit obtained for determination of nine elements in biodiesel by HR-CS FAAS

\begin{tabular}{|c|c|c|c|c|c|}
\hline Analyte & Sensitivity (s L mg ${ }^{-1}$ ) & $R$ & $C_{0}^{\mathrm{a}}\left(\mathrm{mg} \mathrm{L}^{-1}\right)$ & $\mathrm{LOD}^{\mathrm{b}}\left(\mathrm{mg} \mathrm{kg}^{-1}\right)$ & $\mathrm{LOQ}^{\mathrm{c}}\left(\mathrm{mg} \mathrm{kg}^{-1}\right)$ \\
\hline $\mathrm{Zn}$ & 0.7327 & 0.9993 & 0.01 & 0.09 & 0.29 \\
\hline $\mathrm{Fe}$ & 0.0864 & 0.9970 & 0.06 & 0.31 & 1.02 \\
\hline $\mathrm{Mg}$ & 2.4255 & 0.9983 & 0.001 & 0.03 & 0.11 \\
\hline $\mathrm{Cu}$ & 0.3356 & 0.9993 & 0.01 & 0.05 & 0.15 \\
\hline $\mathrm{Na}$ & 1.5025 & 0.9962 & 0.004 & 0.08 & 0.26 \\
\hline $\mathrm{K}$ & 1.0032 & 0.9976 & 0.004 & 0.08 & 0.27 \\
\hline $\mathrm{Cr}$ & 0.1157 & 0.9952 & 0.05 & 1.00 & 3.20 \\
\hline $\mathrm{Al}$ & 0.0159 & 0.9996 & 0.27 & 2.06 & 6.85 \\
\hline $\mathrm{Ca}$ & 0.6354 & 0.9979 & 0.01 & 0.07 & 0.20 \\
\hline
\end{tabular}

${ }^{\mathrm{a}} C_{0}$ : Characteristic concentration, LOD: Limit of detection, LOQ: Limit of quantification. The ${ }^{\mathrm{b}} \mathrm{LOD}$ and ${ }^{\mathrm{c}} \mathrm{LOQ}$ of the method were calculated considering the sample mass of $1.7 \mathrm{~g}$ and a volume of $10 \mathrm{~mL}$, used in the ME preparation.

Table 3. Determination of $\mathrm{Zn}, \mathrm{Fe}, \mathrm{Cu}, \mathrm{Cr}$ and $\mathrm{Al}$ in the spiked samples by HR-CS FAAS using microemulsion (ME) and acid digestion (AD) methods. Results expressed in $\mathrm{mg} \mathrm{kg}^{-1} \pm \mathrm{SD}(\mathrm{n}=3)$

\begin{tabular}{|c|c|c|c|c|c|c|}
\hline Sample & Method & $\mathrm{Zn}$ & $\mathrm{Fe}$ & $\mathrm{Cu}$ & $\mathrm{Cr}$ & $\mathrm{Al}$ \\
\hline \multirow{2}{*}{ B-01 + Spike $1^{\mathrm{a}}$} & $\mathrm{ME}$ & $0.25 \pm 0.03$ & $1.22 \pm 0.07$ & $0.95 \pm 0.03$ & $1.72 \pm 0.09$ & $8.64 \pm 0.32$ \\
\hline & $\mathrm{AD}$ & $0.25 \pm 0.01$ & $1.14 \pm 0.04$ & $1.08 \pm 0.02$ & $1.52 \pm 0.06$ & $8.08 \pm 0.52$ \\
\hline \multirow{2}{*}{ B-01 + Spike $2^{\mathrm{b}}$} & $\mathrm{ME}$ & $0.50 \pm 0.01$ & $2.38 \pm 0.03$ & $1.88 \pm 0.04$ & $3.46 \pm 0.11$ & $14.8 \pm 1.05$ \\
\hline & $\mathrm{AD}$ & $0.49 \pm 0.04$ & $2.33 \pm 0.10$ & $1.78 \pm 0.05$ & $3.29 \pm 0.12$ & $14.5 \pm 0.84$ \\
\hline \multirow{2}{*}{$\mathrm{M}-01+$ Spike $1^{\mathrm{a}}$} & ME & $0.24 \pm 0.02$ & $1.15 \pm 0.07$ & $0.95 \pm 0.08$ & $1.92 \pm 0.05$ & $8.56 \pm 0.44$ \\
\hline & $\mathrm{AD}$ & $0.24 \pm 0.01$ & $1.16 \pm 0.01$ & $1.06 \pm 0.04$ & $1.73 \pm 0.07$ & $8.32 \pm 0.48$ \\
\hline \multirow{2}{*}{$\mathrm{M}-01+$ Spike $2^{\mathrm{b}}$} & $\mathrm{ME}$ & $0.49 \pm 0.01$ & $2.25 \pm 0.05$ & $1.84 \pm 0.03$ & $3.50 \pm 0.12$ & $14.0 \pm 1.00$ \\
\hline & $\mathrm{AD}$ & $0.53 \pm 0.03$ & $2.35 \pm 0.06$ & $2.08 \pm 0.14$ & $3.46 \pm 0.15$ & $14.0 \pm 0.84$ \\
\hline
\end{tabular}

a Spike 1: $0.25 \mathrm{mg} \mathrm{L}^{-1} \mathrm{Zn} ; 1.2 \mathrm{mg} \mathrm{L}^{-1} \mathrm{Fe} ; 1.0 \mathrm{mg} \mathrm{L}^{-1} \mathrm{Cu} ; 1.75 \mathrm{mg} \mathrm{L}^{-1} \mathrm{Cr}$ and $8.0 \mathrm{mg} \mathrm{L}^{-1} \mathrm{Al}$; ${ }^{\text {b }}$ Spike 2: $0.50 \mathrm{mg} \mathrm{L}^{-1} \mathrm{Zn} ; 2.4 \mathrm{mg} \mathrm{L}^{-1} \mathrm{Fe} ; 2.0 \mathrm{mg} \mathrm{L}{ }^{-1} \mathrm{Cu}_{3} 3.5 \mathrm{mg} \mathrm{L}^{-1}$ $\mathrm{Cr}$ and $14.0 \mathrm{mg} \mathrm{L}^{-1} \mathrm{Al}$. 
paired Student's $t$-test $(t$-critical $=3.18$ and $t$-calculated for $\mathrm{Zn}=0.67$; $\mathrm{Fe}=0.12 ; \mathrm{Cu}=1.33 ; \mathrm{Cr}=1.36$ and $\mathrm{Al}=2.39)$. Recoveries of analytes added to biodiesel samples varied between $89 \%$ and $110 \%$ for ME and between $87 \%$ and $108 \%$ for acid digestion methods, which might be considered appropriate for the purpose of this work.

An additional recovery test with inorganic standard added to the ME prepared with sample M-02 was also performed and the obtained results showed satisfatory values ranging from 87 to $114 \%$.

Certified reference materials were also used for the accuracy evaluation of the proposed method (ME) for $\mathrm{K}, \mathrm{Na}, \mathrm{Ca}$ and $\mathrm{Mg}$. The results obtained and compared with the certificated reference materials can be found in Table 4 .

Table 4. Determination of $\mathrm{K}, \mathrm{Na}, \mathrm{Ca}$ and $\mathrm{Mg}$ in biodiesel CRM using ME by HR-CS FAAS $(\mathrm{n}=3)$

\begin{tabular}{lccc}
\hline CRM & Analyte & $\begin{array}{c}\text { Certified value } \\
\left(\mathrm{mg} \mathrm{kg}^{-1}\right)^{\mathrm{a}}\end{array}$ & $\begin{array}{c}\text { Obtained value } \\
\left(\mathrm{mg} \mathrm{kg}^{-1}\right)\end{array}$ \\
\hline BDM2A & $\mathrm{K}$ & $50 \pm 1.0$ & $54.0 \pm 3.2$ \\
& $\mathrm{Na}$ & $50 \pm 1.0$ & $55.7 \pm 3.1$ \\
\hline \multirow{2}{*}{ BDM2B } & $\mathrm{Ca}$ & $50 \pm 1.0$ & $50.8 \pm 0.8$ \\
& $\mathrm{Mg}$ & $50 \pm 1.0$ & $51.4 \pm 4.7$ \\
\hline
\end{tabular}

${ }^{a}$ the associate uncertainty of both CRMs is $\pm 2 \%$.

The obtained values are not significantly different at the $95 \%$ confidence level, according Student's $t$-test $(t$-critical $=4.30$ and $t$-calculated for: $\mathrm{K}=2.17 ; \mathrm{Na}=3.18 ; \mathrm{Ca}=1.73$ and $\mathrm{Mg}=0.52$ ). Additionally, these results confirm the accuracy of the method and corroborate the possibility of using aqueous standards for calibration.

The RSD for the obtained values of concentration for $\mathrm{Zn}, \mathrm{Fe}, \mathrm{Mg}$, $\mathrm{Cu}, \mathrm{Na}, \mathrm{K}, \mathrm{Cr}, \mathrm{Al}$ and $\mathrm{Ca}$ in biodiesel samples using ME by HR-CS FAAS using the results obtained in Tables 3 and 4, were less than $9 \%$, which is in agreement with the values reported in the literature. ${ }^{12,14,15}$

\section{Analytical application}

Ten biodiesel samples from different origins were analysed by HR-CS FAAS using the ME as sample preparation. Four samples (B-01, B-03, M-02 and M-03) did not present any concentration of the analytes above the LOD. The concentrations found for $\mathrm{Fe}, \mathrm{Na}$, $\mathrm{K}$ and $\mathrm{Ca}$ in the other six samples are shown in Table 5. As can be seen, $\mathrm{Na}$ and $\mathrm{K}$ (elements used in the biodiesel production), was found in almost all six samples, $\mathrm{Ca}$ (naturally found in the sources of biodiesel) was found in two samples and $\mathrm{Fe}$ (from the storage tanks) was found in just one sample, in concentrations above of the LOD. According Brazilian Legislation there are only defined limits for the amounts of $\mathrm{Na}+\mathrm{K}\left(5 \mathrm{mg} \mathrm{kg}^{-1}\right)$ and $\mathrm{Ca}+\mathrm{Mg}\left(5 \mathrm{mg} \mathrm{kg}^{-1}\right)$ in biodiesel samples. ${ }^{27}$ The elements $\mathrm{Zn}, \mathrm{Mg}, \mathrm{Cu}, \mathrm{Cr}$ and $\mathrm{Al}$ were not found in any analysed sample in concentrations above the LOD obtained by the method. Nevertheless, many published papers ${ }^{8,15,17}$ have reported concentrations above the LOD found in this work for $\mathrm{Zn}, \mathrm{Cu}, \mathrm{Mg}$ in biodiesel samples, proving that the proposed method is feasible for this application. The less favourable situation is for $\mathrm{Al}$ and $\mathrm{Cr}$, due to the higher LOD obtained for these elements; just one paper reported concentrations above the LOD for $\mathrm{Al}^{28}$ and $\mathrm{Cr} .{ }^{19}$

The samples C-01, C-02 and C-03 were prepared by a research group with used cooking oil using three different methods of production, what explain the high amount of $\mathrm{Na}$ and $\mathrm{K}$ found in two of them; these concentrations were above the limits permitted by Brazilian Legislation. These concentrations (except for $\mathrm{K}$ in sample C-01 and C-02) are similar to results reported for biodiesel analysis in the literature for $\mathrm{Na}, \mathrm{K}, \mathrm{Fe}$ and $\mathrm{Ca} \cdot{ }^{4,6,14,15,19}$ It must be pointed
Table 5. Determination of $\mathrm{Fe}, \mathrm{Na}, \mathrm{K}$ and $\mathrm{Ca}$ in biodiesel using $\mathrm{ME}$ by HR-CS FAAS $(n=3)$

\begin{tabular}{ccccc}
\hline \multirow{2}{*}{ Sample } & \multicolumn{4}{c}{ Concentration $\left(\mathrm{mg} \mathrm{kg}^{-1}\right)($ mean $\pm \mathrm{SD})$} \\
\cline { 2 - 5 } & $\mathrm{Fe}$ & $\mathrm{Na}$ & $\mathrm{K}$ & $\mathrm{Ca}$ \\
\hline $\mathrm{B}-02$ & $<1.02$ & $0.68 \pm 0.03$ & $<0.27$ & $1.54 \pm 0.10$ \\
$\mathrm{M}-01$ & $<1.02$ & $0.91 \pm 0.03$ & $0.47 \pm 0.01$ & $0.97 \pm 0.03$ \\
$\mathrm{M}-04$ & $1.12 \pm 0.02$ & $1.56 \pm 0.01$ & $0.30 \pm 0.01$ & $<0.20$ \\
$\mathrm{C}-01$ & $<1.02$ & $1.14 \pm 0.01$ & $15.5 \pm 0.9$ & $<0.20$ \\
$\mathrm{C}-02$ & $<1.02$ & $2.17 \pm 0.11$ & $12.0 \pm 0.7$ & $<0.20$ \\
$\mathrm{C}-03$ & $<1.02$ & $0.63 \pm 0.03$ & $<0.27$ & $<0.20$ \\
\hline
\end{tabular}

out that with more sensitive techniques some concentrations of the elements which were not found with this technique can be found, as example for $\mathrm{Zn}, \mathrm{Cu}, \mathrm{Cr}$ and $\mathrm{Al}$ determined by ICP techniques, provided that an adequate change in the energy conditions of the plasma and/or the addition of oxygen to the carrier argon stream have been done for correcting matrix effects caused by the high carbon load due to biodiesel microemulsions. ${ }^{8,20,22}$ The proposed method using HR-CS FAAS provided accurate results that are in agreement with alternative methods, making this procedure highly suitable for routine application.

\section{CONCLUSION}

The proposed method makes possible the accurate sequential determination of $\mathrm{Zn}, \mathrm{Fe}, \mathrm{Mg}, \mathrm{Cu}, \mathrm{Na}, \mathrm{K}, \mathrm{Cr}, \mathrm{Al}$ and $\mathrm{Ca}$ in biodiesel samples by HR-CS FAAS. The ME sample preparation method allowed the use of aqueous inorganic standards instead of organic standards required in the methods based on dilution with organic solvents and avoids the use of concentrated acids for digestion. The sequential multi-element determination, in addition to reduced amount of sample $(2.5 \mathrm{~mL})$ due to the use of the flow injection mode, are the main benefits compared with the conventional F AAS with line source. The total time to determine nine analytes was around 13 min due to the adjustment of wavelengths, flame parameters and composition. The low LOD obtained in this work, in the range of $\mu \mathrm{g} \mathrm{kg}^{-1}$ for most of elements (except for $\mathrm{Al}$ and $\mathrm{Cr}$ ), showed that the method is adequate for this application. This accurate and simple determination makes this procedure highly suitable for routine application.

\section{SUPPLEMENTARY MATERIAL}

Supplementary Material shows the absorbance spectrums for $\mathrm{Fe}$ in sample M-04, Ca and Na in sample B-02 and $\mathrm{K}$ in sample M-01 (Figure 1S) and the optimization of oleic acid mass added to ME to simulate biodiesel matrix in the standards for calibration (Figure 2S). Supplementary material available at http://quimicanova.sbq.org.br. Open access.

\section{ACKNOWLEDGMENTS}

This work was supported by the Conselho Nacional de Desenvolvimento Científico e Tecnológico (CNPq Edital 40/2013 grant no. 405011/2013-0 and Universal 2012 grant no. 478998/2012-0) and by the Coordenação de Aperfeiçoamento de Pessoal de Nível Superior - Brasil (CAPES - Finance Code 001). M.M.S. has research scholarships from CNPq (grant no.311269/2019-2). D.O.L. and A.J. had research scholarship from Programa Nacional de Pós-Doutorado da Coordenação de Aperfeiçoamento de Pessoal de Nível Superior 
(PNPD/CAPES) and A.V.Z. had a research scholarship from Projeto ANP-UFRGS.

\section{REFERENCES}

1. Quadros, D. P. C.; Rau, M.; Idrees, M.; Chaves, E. S.; Curtius, A. J.; Borges, D. L. G.; Spectrochim. Acta, Part B. 2011, 66, 373.

2. Gebremariam, S. N.; Marchetti, J. M.; Energy Convers. Manage. 2018, 168,74 .

3. Brazilian National Agency of Petroleum, Natural Gas and Biofuels (ANP): Resoluções ANP: $n^{\circ} 30,23 / 06 / 2016$ and n 16, 29/10/2018. (in Portuguese).

4. Korn, M. G. A.; Santos, D. C. M. B.; Guida, M. A. B.; Barbosa, I. S.; Passos, M. L. C.; Saraiva, M. L. M. F. S.; Lima, J. L. F. C.; J. Braz. Chem. Soc. 2010, 21, 2278.

5. Demirbas, A.; Biodiesel: A Realistic Fuel Alternative for Diesel Engines; Springer: London, 2007.

6. Lepri, F. G.; Chaves, E. S.; Vieira, M. A.; Ribeiro, A. S.; Curtius, A.; Oliveira, J. L. C. C.; Campos, R. C.; Appl. Spectrosc. Rev. 2011, 46, 175.

7. Quadros, D. P. C.; Borges, D. L. G.; J. Braz. Chem. Soc. 2013, 24, 2033.

8. Sánchez, R.; Sánchez, C.; Lienemann, C. P.; Todoli, J. L.; J. Anal. At. Spectrom. 2015, 30, 64.

9. Cassella, R. J.; Brum, D. M.; Robaina, N. F.; Rocha, A. A.; Lima, C. F.; J. Anal. At. Spectrom. 2012, 27, 364.

10. Zmozinski, A. V.; de Jesus, A.; Vale, M. G. R.; Silva, M. M.; Talanta 2010, 83, 637.

11. Viana, C.; Bohrer, D.; Carvalho, L. M.; Nascimento, P. C.; Rosa, M. B.; Trends Anal. Chem. 2014, 53, 49.

12. Aucélio, R. Q.; Doyle, A.; Pizzorno, B. S.; Tristão, M. L. B.; Campos, R. C.; Microchem J. 2004, 78, 21.

13. de Jesus, A.; Vale, M. G. R.; Silva, M. M.; Talanta 2008, 74, 1378.
14. Raposo, J. D.; Costa, L. M.; Barbeira, P. J. S.; J. Braz. Chem. Soc. 2015, $26(1), 147$.

15. Antunes, G. A.; dos Santos, H. S.; da Silva, Y. P.; Silva, M. M.; Piatnicki, C. M. S.; Samios, D.; Energy Fuels 2017, 31 (3), 2944.

16. de Jesus, A.; Zmozinski, A. V.; Barbará, J. A.; Vale, M. G. R.; Silva, M. M.; Energy Fuels 2010, 24, 2109.

17. Pereira, F. M.; Zimpeck, R. C.; Brum, D. M.; Cassella, R. J.; Talanta 2013, 117, 32 .

18. Iqbal, J.; Carney, W. A.; LaCaze, S.; Theegala, C. S.; Open Anal. Chem. J. 2010, 4, 18.

19. Barela, P. S.; Silva, N. A.; Pereira, J. S. F.; Marques, J. C.; Rodrigues, L. F.; Moraes, D. P.; Fuel 2017, 204, 85.

20. Amais, R. S.; Garcia, E. E.; Monteiro, M. R.; Nogueira, A. R. A.; Nóbrega, J. A.; Microchem. J. 2010, 96, 146.

21. Oliveira, L. C. C.; Vieira, M. A.; Ribeiro, A. S.; Baptista, P. M. Gonçalves, R. A.; Campos, R. C.; J. Braz. Chem. Soc. 2012, 23 (7), 1400 .

22. Oliveira, L. C. C.; Vieira, M. A.; Ribeiro, A. S.; Lisboa, M. T.; Gonçalves, R. A.; Campos, R. C.; Energy Fuels 2012, 26 (11), 7041.

23. Welz, B.; Vale, M. G. R.; Pereira, E. R.; Castilho, I. N. B.; Dessuy, M. B.; J. Braz. Chem. Soc. 2014, 25 (5), 799.

24. Welz, B.; Becker-Ross, H.; Florek, S.; Heitmann, U. High-Resolution Continuum Source AAS, Wiley-VCH: Weinheim, 2005.

25. Welz, B.; Sperling, M. Atomic Absorption Spectrometry, 3rd ed., WileyVCH: Weinheim, 1998.

26. Knothe, G.; Gerpen, J. V.; Krahl, J.; Ramos, L. P. Manual de Biodiesel; Edgard Blucher: São Paulo, 2006.

27. Brazilian National Agency of Petroleum, Natural Gas and Biofuels (ANP): Resolução ANP n ${ }^{\circ} 45,25 / 08 / 2014$ (in Portuguese).

28. Vakh, C. S.; Bulatov, A. V.; Shishov, A. Y.; Zabrodin, A. V.; Moskvin, L. N.; Fuel 2014, 135, 198. 